\title{
Desafios do Brincar com Idosos: Narrativas de Estudantes de Medicina do Programa Amigos do Sorriso
}

\author{
Challenges of Playing with the Elderly: Medicine Student's \\ Narratives of the Amigos do Sorriso Program
}

\section{PALAVRAS-CHAVE}

- Extensão Comunitária.

- Humanização.

- Educação Médica.

- Ludicidade.

- Envelhecimento.

- Saúde do Idoso.

- Comunicação em Saúde.

- Narrativa.

\author{
Michele Cheh Hui Liang Chung ${ }^{I}(\mathbb{D})$ \\ Mayara Bosquê Marangon ${ }^{I}(\mathbb{D}$ \\ Willian Fernandes Luna ${ }^{I I}(\mathbb{D}$ \\ Roseli Vernasque Bettini ${ }^{I}(\mathbb{D}$ \\ Renata Keiko Watanabe ${ }^{I I I}$ (D) \\ Mariana Miki Shiroma ${ }^{I V}$
}

\begin{abstract}
RESUMO
Introdução: O programa de extensão Amigos do Sorriso foi construído a partir da compreensão da extensão universitária como integrante da formação dos estudantes, ao proporcionar vivências e trocas na aproximação entre a academia e a sociedade em geral. Os participantes são estudantes da área da saúde e desenvolvem atividades lúdicas com foco no processo de humanização, na educação em saúde e nos seus efeitos multiplicadores. Desde 2010, o programa realiza atividades quinzenais numa instituição de longa permanência para idosos (Ilpi), com o objetivo de oportunizar momentos lúdicos, com estratégias criativas e comunicativas, no sentido de ressignificar a velhice por meio do brincar. Este artigo tem como objetivos descrever as vivências e compreender quais foram os aprendizados desenvolvidos pelos estudantes de Medicina nesse âmbito. Método: Trata-se de uma pesquisa qualitativa, desenvolvida a partir de 13 narrativas redigidas entre 2018 e 2019 por estudantes de Medicina que participaram das atividades lúdicas na Ilpi. Realizou-se análise temática de conteúdo dos materiais em diálogo com os referenciais teóricos e a literatura relacionada. Resultados: As três categorias temáticas foram: o brincar com o idoso, construção artesanal da comunicação e partilha entre gerações sobre o envelhecer. Os extensionistas discutiram as diversas formas do brincar, sua relação com a promoção da saúde e as especificidades de desenvolver atividades lúdicas com o idoso. Utilizaram diversas formas de comunicação para interação com os idosos, conversando, ouvindo e contando histórias e respeitando os silêncios, o que provocou encontros e desencontros, todos disparados pelo brincar. Discutiram sobre o processo de envelhecimento, a saúde do idoso, a velhice asilar e o próprio encontro de gerações por meio do qual puderam refletir sobre si mesmos. Conclusões: As atividades na Ilpi proporcionaram aos estudantes a percepção da potência das estratégias lúdicas, promotoras da autonomia e saúde, sem infantilização dos idosos. Possibilitaram o reconhecimento de estratégias para aproximação e vínculo, respeitando limites individuais e coletivos, ao compartilharem histórias e sentimentos de forma empática. Dessa forma, destaca-se o desenvolvimento de competências para o futuro médico, tanto gerais como para o cuidado com as pessoas idosas, no reconhecimento de que todos estão envolvidos no universo do florescer do envelhecimento.
\end{abstract}

\footnotetext{
Faculdade de Medicina de Marília, Marília, São Paulo, Brasil.

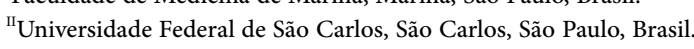

"II Universidade Estadual Paulista “Júlio de Mesquita Filho", Botucatu, São Paulo, Brasil.

${ }^{\text {IV }}$ Hospital Santa Marcelina, São Paulo, Brasil.
} 


\section{KEYWORDS}

- Community Outreach Programs.

- Humanized Care.

- Medical Education.

- Play.

- Aging

- Health of the Elderly.

- Communication in Health.

- Narration.

Recebido em 17/6/20

Aceito em $7 / 10 / 20$

\section{INTRODUÇÃO}

A extensão universitária é uma ação integrante do processo formativo acadêmico que ocorre por meio de vivências que provocam trocas e relações numa realidade social. É espaço de reflexão crítica para repensar ações acadêmicas ante as demandas da sociedade e a formação de futuros profissionais transformadores sociais ${ }^{1}$. No contexto da extensão em saúde, o encontro com a sociedade em suas dificuldades afeta a subjetividade de estudantes, incitando novas estratégias de cuidado do outro e de si, pois, nesse encontro com o diferente e consigo próprios, redescobrem a importância da afetividade nos processos de cura² .

Diversos projetos de extensão universitária distribuídos pelo país têm como foco a humanização no cuidado em saúde e utilizam estratégias como jogos, música, desenho ${ }^{3}$, contação de histórias ${ }^{4}$ ou palhaçoterapia ${ }^{5}$. O conceito de humanização no cuidado em saúde procura instigar a capacidade de oferecer atenção de qualidade, em que se articulam os avanços tecnológicos com o estabelecimento de um vínculo efetivo com o paciente, por meio do aperfeiçoamento das suas habilidades comunicativas. Para tanto, reconhece as necessidades biológicas, emocionais e culturais dos indivíduos, e atua segundo um modelo de atenção que valoriza os processos de mudança dos sujeitos envolvidos na construção da saúde ${ }^{6,7}$. Nesse âmbito, as ações de extensão podem contribuir para aproximar a formação dos profissionais de saúde das humanidades e das posturas críticas e reflexivas, comprometendose com o conceito social de saúde ${ }^{8}$, como descrito nas Diretrizes Curriculares Nacionais para os Cursos de Graduação em Medicina ${ }^{9}$.

Partindo-se dessa compreensão de extensão universitária no âmbito da formação em saúde, desde 2002 tem sido desenvolvido o programa de extensão Amigos do Sorriso, vinculado aos diretórios acadêmicos da

\section{ABSTRACT}

Introduction: The community outreach program Amigos do Sorriso (Friends of Smiling) is based on the understanding that community outreach programs are part of academic training because they provide experiences that result in exchanges between the students and the society. The participants are undergraduate students from the healthcare field, who develop ludic activities focusing on humanization, health education and the resulting multiplying effects. Since 2010, fortnightly activities have been conducted at an old people's home with the aim of offering playful experiences involving creative and communicative strategies, in order to give new meaning to old age through playing. The objective of this article is to describe these experiences and understand what the medicine students have learned from them. Methods: this article presents a qualitative study, based on 13 narratives written between 2018 and 2019 by undergraduate medicine students who were involved in activities at the old people's home. The content was analyzed from a thematic perspective and correlated to the construction of communication and sharing between generations about aging. The participants discussed the different forms of play, its relations with health promotion and the specific characteristics of developing Ludic activities with the elderly. Through play they were also able to explore various forms of communication: talking, listening, sharing stories, and respecting the moments of silence, that led to agreement and disagreement. Finally, they discussed the aging process, elderly heath, elderly people in care and the contact itself between generations, allowing the students to reflect on themselves. Conclusions: The activities in the old people's home enabled the students to appreciate the potential that strategies of play offer in terms of promoting autonomy and health, without infantilizing the elderly. It allowed them to identify strategies to form closer relationships and ties with the elderly subjects, respecting individual and collective boundaries when sharing stories and feelings with empathy. Hence the highlight of the program was the development of skills, both general and specific for elderly care, among future medics, recognizing that the aging is a process that involves us all. 
Iniciadas há dez anos, as atividades de extensão do Programa Amigos do Sorriso na Ilpi acontecem quinzenalmente. Essas atividades acontecem em três etapas: 1. planejamento das atividades a serem realizadas, com elaboração de uma prática lúdica coletiva, que geralmente é um teatro, e definição de um desenho a ser construído com os idosos; 2. execução das atividades lúdicas por cerca de dez extensionistas, aos sábados pela manhã, com duração de três horas; 3 . encontro de supervisão com a psicóloga assessora, de modo a permitir que os extensionistas compartilhem as ações, as vivências e os sentimentos despertados pela atividade e reflitam sobre a experiência.

Sobre a inserção do brincar no cotidiano do idoso, existem outras experiências que buscam promover a autonomia e a saúde, seja em clubes sociais da terceira idade ${ }^{12}$ ou como estratégias de integração ensinocomunidade, como os programas e projetos de extensão na área da saúde. Há registros da atuação de estudantes que inserem atividades lúdicas no cotidiano dessas pessoas, seja por meio de grupos de educação em saúde na atenção básica ${ }^{13}$, como em organizações não governamentais ${ }^{14}$, ou em Ilpi ${ }^{15}$. Nesse contexto, com base nas compreensões de Winnicott ${ }^{16}$, reconhece-se que o brincar é um aspecto universal da natureza humana, quando a criança e o adulto podem desenvolver sua criatividade, possibilitando amadurecimento e integração. Assim, por meio do brincar e do processo criativo, o indivíduo responsabiliza-se pelo mundo e por suas ações, aprendendo a ter mais autonomia e sentindo que a vida é digna de ser vivida ${ }^{17}$.

Portanto, realizou-se esta pesquisa com o objetivo de descrever as atividades criativas e comunicativas realizadas pelos estudantes de Medicina extensionistas do Programa Amigos do Sorriso com os idosos em uma Ilpi, além de compreender os aprendizados desenvolvidos e que podem contribuir para a formação dos futuros médicos.

\section{METODOLOGIA}

Este artigo foi escrito a partir de uma pesquisa exploratória de abordagem qualitativa, desenvolvida por quatro estudantes e dois docentes assessores, todos vinculados ao Programa Amigos do Sorriso. A pesquisa qualitativa possibilita compreender significados e intencionalidades e incorporá-los aos atos e às relações humanas ${ }^{18}$, tendo sido, por esses motivos, escolhida como forma de entender a experiência realizada. $\mathrm{O}$ foco foi a análise de narrativas redigidas por extensionistas que participaram de atividades lúdicas em uma Ilpi.

Adotaram-se as narrativas porque são utilizadas por pessoas para que possam contar suas histórias, individuais ou coletivas, o que leva intimidade ao contexto lúdico dessa experiência. De acordo com Benjamin $^{19}$, a narrativa deriva do intercâmbio de experiências e de contar histórias, incorporando as vivências do próprio narrador ou relatadas por outras pessoas, sem ter o objetivo de transmitir uma informação, mas sim as impressões sobre ela. Sendo assim, a memória é a essência da narrativa que carrega consigo um caráter dinâmico, que absorve as interpretações daquele que narra, podendo ser chamada de uma forma artesanal de comunicação ${ }^{19}$. Ao narrar um acontecimento, o indivíduo reorganiza o que vivenciou, propiciando que seja dado um sentido ao evento, com uma ordem coerente e significativa para ele $^{20}$. Por meio das narrativas, tem-se acesso à experiência do outro de modo indireto, pois a pessoa narra da maneira como a interpretou ${ }^{21}$. Essa especificidade de contextos de produção faz com que as narrativas sejam vistas como uma ação social, permitindo a interpelação de estruturas sociais que integram as experiências, dando espaço para as diferentes posições dos envolvidos e suas interações ${ }^{22}$. Dentre as modalidades de narrativas, optou-se pelas narrativas de vivências, que são amplas, pois o narrador conta vários episódios e não necessariamente tem uma sequência temporal, construindo-se a experiência como um processo ${ }^{23}$.

A coleta dos dados foi realizada em 2018 e 2019, com a finalidade de obter um conjunto suficiente de narrativas para representar, em quantidade e qualidade, as múltiplas dimensões do fenômeno estudado ${ }^{24}$.

Foram convidados todos os 29 extensionistas, há pelo menos um ano no Programa Amigos do Sorriso, que desenvolveram ao menos uma atividade na Ilpi no período entre 2012 e 2018, sendo esses os critérios de inclusão na pesquisa. Realizou-se o contato de forma pessoal e/ou por meio de correio eletrônico, e aos interessados foram enviadas orientações para que redigissem uma narrativa livre sobre suas vivências lúdicas com os idosos, sem que necessariamente relatassem dias específicos, frequência ou quantidade de atividades desenvolvidas. Além disso, foram informados sobre as condições éticas do estudo. Quando as narrativas não eram enviadas, ao menos dois novos convites eram realizados aos extensionistas. Todos os participantes do estudo concordaram com as condições descritas sobre sua participação e assinaram o Termo de Consentimento Livre e Esclarecido.

No processo de pré-análise, utilizaram-se os critérios de exclusão da pesquisa. Das 18 narrativas recebidas, quatro foram excluídas por terem sido escritas por egressos da faculdade e uma por ter sido a única escrita por estudante do curso de Enfermagem. Cabe ressaltar que, inicialmente, a pesquisa incluiria as narrativas dos estudantes de Enfermagem. No entanto, como houve a participação de apenas um voluntário, excluiu-se essa narrativa, restringindo-se às enviadas pelos estudantes de Medicina, já que o material era insuficiente para compreender a diversidade e heterogeneidade do grupo de extensionistas do curso de Enfermagem.

Os participantes (dez mulheres e três homens) que redigiram as 13 narrativas analisadas eram da terceira à sexta série do curso de Medicina e tinham entre 20 e 25 anos. O tempo de atuação no Programa Amigos do Sorriso variou de três a cinco anos. Para garantir o sigilo das informações, foram atribuídos nomes fictícios aos participantes e às pessoas citadas nas narrativas.

Para análise e interpretação do material, optou-se pela análise temática de conteúdo segundo Gomes ${ }^{25}$. Buscou-se caminhar tanto na direção do homogêneo quanto na do heterogêneo, nos seguintes momentos: 1. leitura exaustiva do material, visando impregnar-se pelo conteúdo coletado, o que permitiu uma visão de conjunto e de particularidades; 2. elaboração de mapas conceituais com o intuito de organizar, de modo esquematizado, as ideias, os conceitos e as informações das narrativas ${ }^{26} ; 3$. estabelecimento de categorias de análise temática adequadas ao conteúdo e aos objetivos da pesquisa; 4. decomposição do material em unidades de registro que foram distribuídas entre as categorias; 5 . descrição dos resultados em núcleos de sentido, tendo sido possível realizar inferências e diálogo com os pressupostos teóricos e a literatura relacionada.

Finalizou-se com a inserção de um episódio ilustrativo dos encontros entre extensionistas e idosos na Ilpi, no início de cada uma três das categorias. Os episódios ilustrativos foram construídos a partir de experiências narradas pelos participantes que, sob o olhar dos pesquisadores, poderiam ter um efeito vívido no leitor por conta da descrição de uma vivência específica ${ }^{27}$, relacionada intrinsicamente ao tema da respectiva categoria.

REVISTA BRASILEIRA DE EDUCAÇÃO MÉDICA

3 44 (4) : e170; 2020 
Esta pesquisa foi aprovada no Comitê de Ética e Pesquisa da Famema, sob o Certificado de Apresentação para Apreciação Ética (CAAE) 60847216.0.0000.5413.

\section{RESULTADOS}

Os resultados da análise buscam apresentar as experiências e os aprendizados narrados pelos estudantes de Medicina, tendo sido descritos em três categorias temáticas: o brincar com o idoso; construção artesanal da comunicação; e partilha entre gerações sobre o envelhecer.

\section{Categoria 1: O brincar com o idoso}

Episódio ilustrativo

Foi um fim de semana muito chuvoso. Como o planejamento foi realizado no dia anterior da atividade, decidimos como tema a chuva, abordando o "gostar e o não gostar da chuva", com justificativas construídas pelos personagens dos extensionistas dentro de seus universos. Além disso, construiríamos um grande barco de papel durante a história que contava como a chuva facilita caminhos percorridos pelos barcos por proporcionar a cheia dos rios. Já na parte mais individualizada da atividade, fomos com a ideia de modificar um pouco o formato do desenho, pois construiríamos junto com cada idoso o seu barquinho de papel, orientando os que conseguiam ter mais habilidade manual e auxiliando os que tinham limitações, com o objetivo de cada um pintar o seu barquinho. Foi uma atividade muito prazerosa, pois houve grande participação dos idosos que se viram envolvidos pela construção dos barquinhos e se mostraram um pouco mais abertos a histórias e interação com os integrantes do grupo. Alguns deles quiseram deixar os barquinhos de presente para nós, mas a maioria guardou de recordação. Encerramos a atividade deixando nosso grande barco colorido, construído durante o teatro, amparado ao lado do lago de carpas na área social do Lar (Yasmim).

Nessa primeira categoria, apresentam-se as diversas formas do brincar, sua relação com a promoção de saúde e as especificidades do desenvolvimento com o idoso, visto que o brincar é comumente associado à infância e não à velhice. Os núcleos de sentido transitaram entre os planejamentos, as atividades lúdicas coletivas e as interações individualizadas.

A partir da análise das narrativas, percebeu-se que o brincar foi a abordagem principal que os extensionistas utilizaram para desenvolver as atividades criativas e comunicativas. Destacaram que realizavam planejamento prévio para construir um momento coletivo - o teatro - e um momento individual - o desenho construído com o idoso (DCI):

No planejamento, organizávamos um roteiro de um teatro, com temas que remetiam às lembranças dos idosos. Viagens, interior, música, festas, datas comemorativas... Além da encenação, colocávamos no roteiro a "música do Passarinho", cuja coreografia é composta por exercícios que auxiliam na prevenção das quedas. A maior parte do tempo era destinada ao DCI, momento no qual conseguíamos conversar individualmente com cada idoso, enquanto eles contavam histórias e mais histórias que lembravam durante a atividade (Tainá).

O planejamento das atividades foi descrito como uma forma de trazer segurança aos estudantes de Medicina que enfrentavam o desafio do brincar com o idoso, propondo práticas lúdicas de acordo com as especificidades dos moradores da Ilpi, que também propiciaram improvisos:

Como estávamos no mês de junho, começamos a falar sobre as festas juninas, sobre o campo. Convidamos os idosos a dançar quadrilha e ajudamos quem tinha dificuldades de movimentação. Os idosos que não conseguiam andar, eles participariam batendo palmas e cantando, reconhecendo a limitação de cada um. [...] Mas também improvisávamos quando necessário (Isabel).

O momento liminar do teatro tinha o objetivo de possibilitar interação social e promoção de bem-estar físico e mental, o que está intimamente ligado à melhora da qualidade de vida dos idosos, e os extensionistas relataram que perceberam o fortalecimento da autonomia e reflexão entre os idosos. Nesse sentido, foi destacada a importância de que os trabalhos lúdicos realizados pudessem ser estimulantes cognitivos, respeitando as limitações físicas e mentais dos idosos ${ }^{28}$. Nessa busca de interação com os moradores, remetia-se a memórias antigas ou relativamente recentes, como músicas ouvidas nas rádios e lembranças de outras atividades com os extensionistas, em visitas anteriores:

\footnotetext{
Buscávamos criar teatros que interagissem com os idosos e que eles se envolvessem em uma realidade diferente da que eles se encontravam, lembrando de outros momentos (Cláudia).

Durante a encenação, tentávamos buscar a participação dos idosos pedindo dicas de músicas, ajuda para sair das situações que criávamos ou fazendo perguntas para estimular as lembranças deles (Tainá).
}

Dessa forma, pôde-se reconhecer o brincar como estratégia de promoção de saúde. A música do "Passarinho", além de desenvolver os movimentos para prevenção de quedas, como relatado pelos extensionistas, também resgatava a memória recente, pois muitos moradores já a conheciam e pediam que fosse cantada, recuperando inclusive brincadeiras de sua infância:

Cantamos essa música, pois os idosos já a conhecem e realizam os movimentos que ela propõe (Isabel).

Durante a atividade, me diverti muito em ouvir os moradores rindo, contando do que brincavam, lembrando de suas infâncias (Alan).

Após a prática lúdica coletiva, dava-se início ao brincar de forma mais individualizada, utilizando-se estratégias artísticas, como o desenhar e o pintar. Nesse momento mais íntimo, o extensionista e o morador enfrentavam juntos os desafios da senescência e senilidade ao construírem arte:

Uma das senhoras com quem sentei quis desenhar uma flor (de maneira muito elegante, quase profissional) e perguntei como e por que ela desenhava uma flor tão bonita. A resposta dela foi que ela gostava de flores, que o desenho era bom, pois ela havia

REVISTA BRASILEIRA DE EDUCAÇÃO MÉDICA

4 44 (4) : e170; 2020 
trabalhado como estilista e desenhar era uma das únicas coisas que gostava (Cássia).

Apesar de as atividades serem pré-programadas e possuírem uma estrutura padrão, percebeu-se que elas não eram rígidas nem restritas ao planejamento. Tanto o extensionista quanto o idoso narravam as próprias experiências pessoais. Munidos de criatividade, transformavam os momentos e criavam novas possibilidades, como construir um barquinho em vez de desenhá-lo, conforme exemplificado no episódio ilustrativo do início dessa categoria.

Dessa maneira, a introdução de atividades lúdicas, como as descritas nas narrativas, pôde acalentar, ainda que momentaneamente, essa carência, com o cuidado de garantir o respeito e a autonomia dos idosos, por meio de um brincar que não os infantilizasse:

Outra questão que eu tinha dificuldade é não infantilizar os idosos. No começo, tinha muito receio de o teatro ser meio "ridículo" para eles, como se estivesse os subestimando (Maria).

Vejo o quanto as atividades desse cenário são importantes para os idosos que muitas vezes se divertem com as histórias ou encontram em nós ouvidos para ouvi-los (Ricardo).

Portanto, no desenvolvimento das práticas lúdicas com os idosos, superaram-se algumas limitações, tonando possível a construção de espaços criativos, com vistas ao surgimento de interações mais afetivas.

Categoria 2: Construção artesanal da comunicação

Episódio ilustrativo

Entrei na cozinha desejando bom dia para a senhora que estava sentada na mesa e ela respondeu: “Como vai sua tia?". Entrei na brincadeira: "Debaixo da pia, comendo melancia." A senhora esboçou um pequeno sorriso, mas manteve sua feição de brava. Sentei na sua frente, na mesma posição, com os braços apoiados na mesa sustentando o rosto. Ela disse que não queria conversar e eu respondi que também não, que só estava sentado. Ela sorriu e ficou me olhando. Após uns três minutos quietos, se encarando, ela começou a continuar o bordão: "Bom dia. Como vai sua tia? Debaixo da pia, comendo melancia, sentada na bacia...”. Ajudei-a nessa construção e começamos a conversar. Seu humor irritadiço foi desaparecendo. Aquela senhora me deixou extremamente instigado, queria desvendar aquele humor ácido, aquela cara de brava lutando contra a saída de um sorriso (Alan).

Nessa segunda categoria, são apresentadas as construções artesanais utilizadas para interação individual com os idosos. Os núcleos de sentido apresentaram conversas e silêncios, encontros e desencontros, disparados pelo brincar.

$\mathrm{Na}$ comunicação, a troca de informações entre as pessoas é capaz de construir e decodificar significados, promovendo crescimento e desenvolvimento humanos ${ }^{29}$. Nos encontros entre os estudantes de Medicina e os idosos da Ilpi, isso não foi diferente, embora haja peculiaridades desse processo de interação destacadas ao longo da categoria. A responsabilidade individual pela condução da conversa gerava mais insegurança e expectativas do que as atividades coletivas:

O que me deixava preocupada seria a parte de interação individual, de como interagir de forma mais próxima com o idoso durante a conversa (Yasmim).

Conforme mostrado no episódio ilustrativo dessa categoria, as conversas e as atividades lúdicas não eram momentos isolados, mas desenvolviam-se de acordo com as necessidades e singularidades do encontro. Naturalmente, as atividades lúdicas iam se desenrolando em conversas, quando os interlocutores falavam e eram escutados, numa relação de interesse e horizontalidade. Esse caminho propiciou o fortalecimento da postura ativa de ambos, em uma troca de saberes no reconhecimento de suas diferenças ${ }^{30}$, respeitando inclusive os silêncios necessários:

A partir do desenho ou algo relacionado ao teatro, começamos a conversar sobre sua vida sem que houvesse a necessidade de perguntar. Ela queria compartilhar sobre sua vida, relembrar o passado. Simplesmente conversar (Cássia).

Meu problema nunca foi estar com velhos, conversar com eles é natural pra mim. Qualquer boa tarde é desculpa pra uma conversa mais longa (Lorena).

Em algumas situações a conversa pode ser longa, divertida ou envolvente, porém, em outras, precisamos saber lidar com o silêncio, com perguntas não respondidas e com a percepção da comunicação falha ou inexistente (Ricardo).

$\mathrm{O}$ processo de envelhecimento se relaciona com alterações da capacidade funcional do indivíduo, em que estão envolvidos aspectos biológicos - tais como o comprometimento sensório-perceptivo, as doenças crônico-degenerativas e as reduções hormonais - e aspectos psicológicos, na medida em que o idoso encara a progressiva perda de independência na realização de algumas atividades diárias. Essa condição influenciou o processo de comunicação, e, para que essas dificuldades não refletissem na exclusão social do idoso ${ }^{31}$, demandaram-se adaptações a partir do reconhecimento das limitações:

Passei a me questionar o que poderia ser adaptado para acompanhar essa piora clínica de nossos idosos; para as pessoas que antes pintavam e conversavam e que agora já não conseguiam mais. Quais atividades seriam pertinentes? (Sandra).

Eu aproveito para conversar sobre o que ele quiser e dou o tempo necessário para ele responder de forma que eu não o apresse ou interrompa seu raciocínio. Além disso, preciso ter paciência para repetir a pergunta ou a resposta para o idoso quantas vezes for necessário, assim tento repetir de forma parecida para que não o confunda (Isabel).

Fico um pouco preocupado se estão conseguindo compreender a mensagem ou mesmo ouvir nossas falas. Um dos maiores desafios para mim são as dificuldades na comunicação com uma boa parte daquelas pessoas, seja verbal ou mesmo visual (Ricardo).

Além de superarem as limitações físicas e cognitivas durante as 
conversas, os extensionistas enfrentaram outras questões numa diversidade de mecanismos de linguagem, conteúdo dos assuntos e sentimentos despertados. Dessa forma, as conversas poderiam ou não ser aprofundadas:

Minha maior dificuldade era a preocupação em fazê-los entender tudo o que falamos. Muitas gírias e vícios de linguagem, músicas novas, ou o próprio falar muito rápido ou baixo podiam comprometer o entendimento deles (Tainá).

Percebe-se como a realidade deles é diferente da minha. Às vezes a conversa se mantém no "superficial", e é até fácil seguir assim. Mas, quando há comentários que mostram coisas mais profundas, mais particulares, é um conteúdo totalmente diferente para conversar (Maria).

Nesse ínterim, percebeu-se que os assuntos trazidos pelos idosos estavam muito relacionados às suas memórias e lembranças do passado, num processo de narrar suas vivências. Assim, os extensionistas tinham a oportunidade de conhecer sobre importantes momentos históricos para aquelas pessoas, valorizando essa narração que dava identidade a cada uma delas, num exercício de reconhecimento do outro, atenção e interpretação de histórias, no desenvolvimento de uma competência narrativa ${ }^{32}$ :

A grande maioria traz o seu passado, as suas recordações. De certa forma, sinto que, quando eles falam destas memórias, momentos importantes de suas vidas são revividos. Por isso, para mim, escutá-los é especial, quase sagrado, porque enxergamos este processo acontecer (José).

Fui tendo um olhar mais atento para as dificuldades particulares dos que estão ao meu redor [...] recebendo e compartilhando histórias tão humanas e que no final contribuem para o desenvolvimento de habilidades comunicativas (Ricardo).

Para os estudantes de Medicina, entrar em contato com essas narrativas aflorou suas subjetividades, melhorando sua capacidade de lidar com limitações e mantendo a autonomia do interlocutor, numa compreensão ampliada da linguagem ${ }^{33}$ e possibilitando o desenvolvimento dessas e outras habilidades de comunicação.

Categoria 3: Partilha entre gerações sobre o envelhecer

Episódio ilustrativo

Entrar no asilo nunca foi fácil. Não pelos velhos, mas pelo ambiente. Muitas vezes me senti como um remendo que estava lá para suprir a carência de pessoas abandonadas pelo mundo, mesmo que o Lar tenha bom cuidado e estrutura. Dentre os idosos que conheci, há duas memórias muito vívidas porque eram extremos: Dona Catarina e Dona Josefa. Dona Catarina foi enfermeira, não constituiu prole, viveu para trabalhar e por opção resolveu morar no asilo, não aceitava a solidão e o sorriso era estampado no seu rosto. Participativa, se deixava envolver pelas brincadeiras, conversava com todos à sua volta, pintava o desenho com prazer, conversou por longos minutos comigo e muitos outros. Não consigo dizer se foi no mesmo dia, mas sentei em um dos sofás para conversar com Dona Josefa, que não estava muito animada para pintar. Não sei se foi justamente a minha angústia de estar em um estabelecimento que vai contra tudo que acredito sobre envelhecer que me aproximou dela. Não sei como, mas, em certo momento, me contou de sua casinha e de como tinha saudade. Chorou. Chorou a saudade de casa. Chorou ter sido tirada de casa. Chorou a solidão. Chorou a saudade da irmã. Chorou estar confinada no asilo e meu coração chorou junto (Lorena).

Nessa terceira categoria, o foco são as diversas compreensões sobre o envelhecimento nesse encontro entre idoso e estudante. Os núcleos de sentido trouxeram questões sobre o envelhecimento e a saúde do idoso, a velhice asilar e o próprio encontro de gerações, quando os extensionistas foram provocados a refletir sobre si mesmos.

Reconhecer o processo de envelhecimento individual e identificar as fragilidades e especificidades desse grupo foi marcante nas narrativas dos estudantes de Medicina, pois tinham oportunidade de estar com pessoas mais velhas, não numa relação entre profissional e paciente, mas em um encontro entre pessoas de gerações diferentes, o que ainda é pouco presente na maioria das graduações na área da saúde ${ }^{34}$. Nessa interação, experienciaram a complexidade e diversidade dessa etapa da vida:

Nem tudo eram flores, também voltava das atividades com alguns sentimentos de desconforto, ao ver muitos idosos debilitados física e cognitivamente, com relações familiares fragilizadas e olhares tristes e vazios (Joice).

Aquelas pessoas superlúcidas e extremamente carentes [...] me ensinavam sobre o que é o envelhecimento e que cada pessoa vive isso de uma forma. Eu passei a enxergá-los não só como pacientes idosos, mas como indivíduos (Alan).

A vivência dos extensionistas na Ilpi proporcionou uma aproximação ao universo desses idosos, cujas narrativas envolviam, por vezes, a perda dos vínculos afetivos e/ou familiares, a solidão e o abandono:

Eu senti certa tristeza [...], pois muitos idosos no Lar são
abandonados por suas famílias (Isabel).

Me falou de onde era, sobre amizades antigas, que o marido havia morrido há anos, que os filhos a colocaram na Ilpi, mas nunca a visitavam. Que não tinha amigos próximos que pudessem visitála e não conversava com eles há anos. Que sentia falta de muito e atualmente gostava de pouco (Cássia).

Nesse reconhecimento da velhice asilar, os estudantes se aproximaram das diversas trajetórias e experiências desses idosos, como descrito no episódio ilustrativo. Nesse processo, não se afloraram apenas rupturas, mas também novas possibilidades nesse ambiente institucional em que é possível a criação de novos laços entre pessoas muito heterogêneas, o que é característico desse segmento etário por causa das diferentes trajetórias de vida ${ }^{35}$ :

Eu percebi que no Lar tem diversos tipos de idosos, aqueles mais extrovertidos ou introvertidos, outros felizes por morar nesse local e alguns tristes por serem abandonados pelos familiares (Isabel).

Com o maior contato com os idosos do asilo, essa ideia de que o envelhecer é "parar" foi sendo substituída por uma ideia de que

REVISTA BRASILEIRA DE EDUCAÇÃO MÉDICA

6 $64(4):$ e170; 2020 
a "velhice" é muito mais; é uma continuidade, ainda se vive. [...] Criam novas amizades, divertem-se nas "aulas" e atividades que realizam, encontram novos amores, brigam, desenvolvem novos hobbies... Devo dizer que encontrei um envelhecimento cheio de vida, ao contrário da minha interpretação das experiências passadas (Maria).

Nesse ambiente de complexidade de relações, as narrativas destacaram a presença do cuidado em saúde no ambiente da Ilpi, revelando que aquele não era um espaço específico de um serviço de saúde, mas moradia daquelas pessoas, onde viviam o seu cotidiano. Isso fica evidente quando a Ilpi era chamada de "casa" pelos extensionistas:

$A$ arte de cuidar se faz muito presente naquele lugar. Alguns idosos constroem relacionamentos entre si e se cuidam e os cuidadores no asilo também (Cláudia).

Aquelas pessoas, superlúcidas [...] passavam a semana inteira em casa assistindo TV (Alan).

Para além da mudança sobre a compreensão da velhice dos moradores da Ilpi, os extensionistas puderam refletir sobre o envelhecimento de pessoas do seu convívio e/ou de sua família, possibilitando que esse entendimento estivesse mais próximo do seu cotidiano, num ato de relacionar-se com as histórias da própria vida:

É interessante perceber que cada um possui uma relação única com o asilo, de acordo com suas experiências pessoais. No primeiro dia que participei dessa atividade, estava com muito receio, pois sei que lá há várias pessoas com algum tipol estágio de demência. Esta doença fez parte de um momento familiar meu bem complicado, desgastando meu relacionamento com a minha avó materna, e até mesmo com a minha mãe (Maria).

Eu sabia que o lidar com idosos era uma coisa que movimentava muita coisa em mim devido a experiências familiares tão dicotômicas com minhas avós, vivenciando vários aspectos característicos do avanço da idade e sua interferência no convívio familiar (Yasmin).

No encontro entre diferentes gerações, os extensionistas narraram reflexões sobre o próprio envelhecimento, descreveram angústias e expectativas sobre essa etapa da vida e demonstraram o desenvolvimento de empatia na possibilidade de se colocarem no lugar do outro:

Quando entro no asilo, consigo enxergar o que pode vir a ser daqui a algumas décadas e reflito a respeito de como irei envelhecer, sobre como quero estar no meu final e como eu gostaria de ter vivido minha vida antes de morrer (José).

No Lar, vemos isso ocorrer de maneira recorrente e nos provoca várias reflexões sobre como estamos vivendo nossa vida enquanto jovens e dos nossos relacionamentos familiares com as pessoas mais velhas do nosso convívio (Cláudia).

O nosso tempo é limitado, apesar de não percebermos isso enquanto jovens [...]. Saindo de lá, o dia tem outro brilho e tomamos nota de que, em essência, seremos sempre os mesmos (Dirce).

Esse estar com o outro evidenciou-se nas narrativas dos estudantes de Medicina quando, levando em conta seus valores culturais e suas experiências familiares, conseguiram adentrar naquelas histórias, vivenciálas e, ao emergirem em sua própria vida, obter novos conhecimentos, significados e possíveis transformações.

\section{DISCUSSÃO}

De acordo com Winnicott ${ }^{16}$, o brincar possibilita quebrar barreiras da realidade, viver experiências, viabilizando transitar entre o subjetivo e o objetivo. Para além da diversão, é a possibilidade de viver uma experiência lúdica que traz prazer a partir do momento em que é significada. E, nesse sentido, o brincar é a própria saúde ${ }^{16}$. No senso comum, o brincar pode assumir múltiplos significados, como divertir-se com jogos infantis; entreter-se com objetos ou atividades lúdicas; simular situações da vida real; distrair-se, folgar, recrear-se $\mathrm{s}^{36}$. Dessa forma, desenvolver as atividades lúdicas com os idosos aconteceu a partir da compreensão atemporal do brincar, sem restrições a faixas etárias e como forma de comunicação e estabelecimento de vínculos.

As atividades lúdicas foram desenvolvidas de forma a valorizar a linguagem e respeitar as limitações funcionais ${ }^{28}$, enfrentando o desafio de não infantilizar os idosos. A comum associação da velhice ao retorno à infância é uma visão que ignora as experiências prévias e as capacidades latentes do idoso, ressaltando apenas a dependência física que a idade muitas vezes impõe. Dessa forma, os extensionistas relataram cuidado na busca de garantir o respeito e a autonomia, superando formas de interação infantilizada, que seriam demonstradas pelo tratamento imperativo, pelo desrespeito às vontades e escolhas individuais e pelo uso de expressões diminutivas, o que seria considerado desvalorização do idoso como um adulto ${ }^{37}$.

Os estudantes de Medicina relataram, inclusive, que perceberam o fortalecimento da autonomia, autoestima, descontração e reflexão entre os idosos, da mesma forma que descrito em outro estudo com atividades lúdicas com idosos ${ }^{14}$. No que tange à saúde do idoso, a preservação da autonomia é essencial, assegurando-se o direito de escolha, o respeito às capacidades e experiências do indivíduo, evitando, assim, que a velhice seja equiparada somente à faceta da dependência ${ }^{37}$. Nesse sentido, Barbosa, Henger et al. ${ }^{12}$ consideraram que a atividade física elaborada adequadamente para idosos é capaz de otimizar os movimentos dos participantes, tendo impacto na prevenção e recuperação em saúde.

Em sua pesquisa com um projeto de extensão em saúde do idoso, Combinato et al. ${ }^{13}$ relataram que a atividade coletiva com idosos, por meio da extensão universitária, foi capaz de resgatar memórias por meio de compartilhamentos de fotografias pessoais ou histórias de vida. Por sua vez Barbosa, Hunger et al. ${ }^{12}$ descreveram que esse resgate acontecia por meio do lúdico, ao retomar brincadeiras de infância e permitir que os idosos pudessem resgatar bons momentos da vida deles, o que também aconteceu nas atividades desenvolvidas pelos extensionistas do Programa Amigos do Sorriso.

Costa, Costa et al. ${ }^{28}$ chamaram a atenção para a necessidade de se reconhecer a Ilpi como moradia dos idosos que lá residem. Nesse sentido, as Ilpi poderiam apresentar insuficiências em relação às necessidades dos

7 REVISTA BRASILEIRA DE EDUCAÇÃO MÉDICA

7 44 (4) : e170; 2020 
moradores, pois, para além dos cuidados básicos, existe uma demanda por escuta, atenção e afeto, o que pôde ser descrito pelos estudantes de Medicina por meio da interação individual que foi propulsionada pelo brincar.

Assim, a comunicação envolve, além das palavras expressas por meio da fala, todos os sinais transmitidos pelas expressões faciais, pela postura corporal e pela distância que se mantém entre as pessoas. A capacidade de tocar e de silenciar em uma conversa é parte da comunicação ${ }^{38}$, sendo um processo complexo que exige cuidado para que as necessidades do outro sejam respeitadas, culminando em uma diversidade de encontros e momentos, em um formato quase artesanal, como descrito pelos estudantes.

No processo de compreensão das falhas comunicativas, é necessário reconhecer que elas estão, na maioria das vezes, ligadas às dificuldades de compreensão da linguagem utilizada e não ao prejuízo na capacidade intelectual do idoso, sendo esse um fator decisivo na forma de tratamento desse indivíduo ${ }^{38}$. Da mesma forma que a pesquisa de Luna, Melo et al. ${ }^{39}$ relatou o desenvolvimento da escuta empática a partir do encontro entre idosos e estudantes de Medicina, os extensionistas do Programa Amigos do Sorriso narraram momentos de interação em que foram expostos ao desafio de criar estratégias adaptativas e criativas de comunicação para superar as barreiras apresentadas, passando a escutar de forma empática e acolhendo aquele idoso, respeitando o tempo imposto por suas limitações ${ }^{40}$.

Nesse contexto, é interessante perceber que, na maioria das vezes, os idosos são mais atentos e treinados em comunicação não verbal do que a população jovem, que valoriza mais as palavras do que os gestos e olhares ${ }^{38}$. Além disso, a superação da linguagem infantilizada era característica marcante na comunicação com os idosos, evitando-se os diminutivos, palavras e expressões primárias de carinho e estereótipos preconceituosos ${ }^{41}$.

Observou-se que, ao narrarem a experiência de encontro, os estudantes de Medicina utilizaram, predominantemente, o termo "idoso", largamente adotado no campo da saúde nas últimas décadas. Em algumas narrativas, percebeu-se o uso da palavra "velho", o que foi relatado como intencional, ressaltando-se que a velhice é um período de sabedoria e maior experiência de vida. Dessa forma, buscou-se a superação da associação hegemônica com a fragilidade e a perda das capacidades funcionais, ressaltando-se associadamente as características positivas dessa etapa da vida ${ }^{42}$.

No encontro entre diferentes gerações, como relatado na pesquisa de Moimaz, Gabin et al. ${ }^{43}$, os extensionistas narraram reflexões sobre o próprio envelhecimento e descreveram angústias e expectativas sobre essa etapa da vida, fenômeno também observado por Luna, Melo et al. ${ }^{39}$ em outra extensão universitária envolvendo uma Ilpi, quando houve desenvolvimento de empatia.

Dessa forma, percebeu-se que as interações entre os estudantes de Medicina e os idosos favoreceram vivências subjetivas e indicaram a possibilidade de autoria da própria vida, na medida em que compartilhar e relembrar histórias promoveu o encontro com o outro e consigo mesmo, construindo um sujeito responsivo e responsável ao existir.

\section{CONSIDERAÇÕES FINAIS}

As narrativas escritas pelos estudantes de Medicina extensionistas do Programa Amigos do Sorriso descreveram a potência das estratégias lúdicas, independentemente da idade e das limitações, pois o brincar possui infindas possibilidades de realçar o aspecto criativo inerente a qualquer faixa etária. Ressaltou-se que para o brincar não foi necessário infantilizar, mas promover autonomia e saúde. Apesar de não investigadas nesta pesquisa, as atividades possivelmente contribuíram para a saúde dos idosos, o que pode ser foco de outros estudos.

Os extensionistas demonstraram preocupação em respeitar os limites estabelecidos de forma coletiva e individual pelos idosos, com atenção e espaço para que fossem ouvidos, compartilhando histórias. Dessa forma, os estudantes de Medicina desenvolveram empatia na relação com o idoso. Afinal, ao ouvirem as histórias de felicidade ou de tristeza, inclusive sobre estar em uma Ilpi, os estudantes puderam vivenciar e compartilhar os sentimentos, o que propiciou a busca por estratégias de aproximação, vínculo e desenvolvimento nas relações.

Houve aprendizado desde o planejamento da atividade, a execução do teatro e a comunicação com o idoso, e foi possível identificar e aprofundar questões nas atividades de supervisão. Destaca-se assim o desenvolvimento de competências para o futuro médico, tais como responsabilidade, escuta, empatia, planejamento, criatividade, reconhecimento de limites pessoais e do paciente, bem como algumas habilidades específicas para trabalhar com a pessoa idosa.

Conclui-se que as atividades lúdicas na extensão universitária com idosos nessa Ilpi têm se mostrado como uma interessante estratégia para promoção da saúde, possibilitando o desenvolvimento de competências importantes para o estudante da área da saúde nesse universo do florescer do envelhecimento.

\section{AGRADECIMENTOS}

A ciência de que a riqueza da vida consiste na troca, que o ser humano é um ser social e por isso nunca está verdadeiramente só, nos leva a crer que esse trabalho seja fruto do compartilhar. Existe uma necessidade de agradecer. Agradecer aos Amigos por dividirem suas memórias. Agradecer aos velhos por serem fonte de estudo e por sua generosidade de compartilhar vida e lembranças por meio do brincar, ato que não se limita pela idade. Agradecer a ILPI por nos ceder tempo e espaço. Dedicamos profunda gratidão a tudo e a todos que em algum momento contribuíram para a nossa construção.

\section{REFERÊNCIAS}

1. Fórum de pró-reitores de extensão das universidades públicas brasileiras. Plano Nacional de Extensão Universitária. Ilhéus: Editus; 2001.

2. Fleuri RM. Formação de profissionais de saúde: reflexões a partir de vivências estudantis. In: Vasconcelos EM, Frota LH, Simon E, organizadores. Perplexidade na universidade: vivências nos cursos de saúde. São Paulo: Hucitec, Mandacaru; 2006. p. 231-64.

3. Amorim KPC, Rocha AKC, Silva ICS, Melo LMB, Araújo MAA. Mediarte com Amor e Humor: uma experiência a partir do olhar dos participantes. Rev Bras Educ Med. 2015;39(2):294-301 [acesso em 29 ago 2020]. Disponível em: https://www.scielo.br/scielo. php?pid=S0100-55022015000200294\&script=sci_abstract\&tlng=pt.

4. Rosevics L, Aguiar DA, Borges CR, Hasegawa Filho R, Yamashita TS, Manchak AC, et al. ProCura - a arte da vida: um projeto pela humanização na saúde. Rev Bras Educ Med. 2014;38(4):486-92 [acesso em 29 ago 2020]. Disponível em: https://www.scielo.br/scielo. php?pid=S0100-55022014000400010\&script=sci_abstract\&tlng=pt. 
5. Takahagui FM, Moraes ENS, Beraldi GH, Akamine GK, Basile MA, Scivoletto S. MadAlegria - estudantes de medicina atuando como doutores-palhaços: estratégia útil para humanização do ensino médico? Rev Bras Educ Med. 2014;38(1):120-6 [acesso em 29 ago 2020]. Disponível em: https://www.scielo.br/scielo.php?script=sci_ arttext\&pid=S0100-55022014000100016.

6. Deslandes SF. Análise do discurso oficial sobre a humanização da assistência hospitalar. Ciênc Saúde Colet. 2004;9(1):7-14 [acesso em 29 ago 2020]. Disponível em: https://www.scielo.br/scielo. php?script=sci_arttext\&pid=S1413-81232004000100002\&lng=en\&n $\mathrm{rm}=\mathrm{iso} \& \operatorname{lng}=$ pt.

7. Benevides R, Passos E. Humanização na saúde: um novo modismo? Interface (Botucatu). 2005;9(17):389-406 [acesso em 24 ago 2020]. Disponível em: https://www.scielo.br/scielo.php?script=sci_ arttext\&pid=S1414-32832005000200014\&lng=pt\&nrm=iso\&tlng=pt.

8. Ponte CIRV, Torres MA, Machado CLB, Manfroi WC. A extensão universitária na Famed/UFRGS: cenário de formação profissional. Rev Bras Educ Med. 2009;33(4):527-34.

9. Brasil. Resolução CNE/CES n 3, de 20 de junho de 2014. Institui Diretrizes Curriculares Nacionais do Curso de Graduação em Medicina e dá outras providências. Diário oficial da União, Brasília; 20 jun 2014; Seção 1, p. 8-11.

10. Barroso MJR. A iniciativa pública e privada nos serviços de saúde, educação, cultura e lazer. A Terceira Idade. 1999;17(1):28-38.

11. Fernandes APS, Oliveira RC. O idoso e a ludicidade. Publ UEPG Humanit Sci Linguist Lett Arts. 2012;20(2):151-60 [acesso em 29 jan 2020]. Disponível em: https://www.revistas2.uepg.br/index.php/ humanas/article/view/3694/3193.

12. Barbosa NMC, Hunger DACF, Pereira VA. O brincar em diferentes gerações: compartilhando experiências e atividades lúdicas na prática educativa. RBCEH. 2007;4(2):127-35 [acesso em 20 fev 2020]. Disponível em: http://seer.upf.br/index.php/rbceh/article/view/132.

13. Combinato DS, Vecchia MD, Lopes EG, Manoel RA, Marino HD, Oliveira ACS, et al. "Grupos de Conversa": saúde da pessoa idosa na estratégia saúde da família. Psicol Soc. 2010;22(3):558-68 [acesso em 2 mar 2020]. Disponível em: https://www.scielo.br/scielo. php?pid=S0102-71822010000300016\&script=sci_abstract\&tlng=pt.

14. Cyrino RS, Silva LED, Souza MR, Borges CJ, Pereira LTS. Atividades lúdicas como estratégia de educação em saúde com idosos. Rev Ciênc Ext. 2016;12(3):154-63.

15. Guimarães AC, Dutra NS, Silva GLS, Vieira-Silva M, Maia BDC. Atividades grupais com idosos institucionalizados: exercícios físicos funcionais e lúdicos em ação transdisciplinar. Pesqui Prát Psicossociais. 2016;11(2):443-52 [acesso em 13 set 2020]. Disponível em: http://pepsic.bvsalud.org/scielo.php?script=sci_ arttext\&pid=S1809-89082016000200013.

16. Winnicott DW. O brincar \& a realidade. Tradução J. O. A. Abreu e V. Nobre. Rio de Janeiro: Imago; 1975.

17. Fulgencio L. O brincar como modelo do método de tratamento psicanalítico. Rev Bras Psicanál. 2008;42(1):123-36 [acesso em 29 jul 2020]. Disponível em: http://pepsic.bvsalud.org/scielo. php?script=sci_arttext\&pid=S0486-641X2008000100013.

18. Minayo MCS. O desafio do conhecimento: pesquisa qualitativa em saúde. São Paulo: Hucitec; 2006.
19. Benjamin, W. O narrador: considerações sobre a obra de Nicolai Leskov. In: Benjamin, W, organizador. Magia e técnica, arte e política: ensaios sobre literatura e história da cultura. São Paulo: Brasiliense; 2012. p. 213-40.

20. Gancho CV. Como analisar narrativas. São Paulo: Ática; 1998.

21. Garro LC. Narrative representations of chronic illness experience: cultural models of illness, mind, and body in stories concerning the tempero mandibular joint (TMJ). Soc Sci Med. 1994; 38(6):775-88.

22. Castellanos MEP. A narrativa nas pesquisas qualitativas em saúde. Ciênc Saúde Colet. 2014; 19(4):1065-76 [acesso em 27 nov 2018]. Disponível em: https://www.scielo.br/scielo.php?pid=S1413$81232014000401065 \&$ script=sci_abstract\&tlng $=$ pt.

23. Lira GV, Catrib AMF, Nations MK. A narrativa na pesquisa social em saúde: perspectiva e método. Rev Bras Promoç Saúde. 2003;16(12):59-66 [acesso em 27 nov 2018]. Disponível em: https://periodicos. unifor.br/RBPS/article/view/333/2035.

24. Minayo MCS. Amostragem e saturação em pesquisa qualitativa: consensos e controvérsias. Revista Pesquisa Qualitativa. 2017;5(7):112 [acesso em 7 out 2019]. Disponível em: https://editora.sepq.org. br/index.php/rpq/article/view/82/59.

25. Gomes R. Análise e Interpretação de dados em pesquisa qualitativa. In: Minayo MCS, organizadora. Pesquisa Social: teoria, método e criatividade. Petrópolis: Vozes; 2012. p. 67-80.

26. Moreira MA. Mapas conceituais e aprendizagem significativa. São Paulo: Cantauro; 2010.

27. Pereira PS. $O$ amor na relação terapêutica em enfermagem: experiência vivida do enfermeiro de saúde mental [tese]. Lisboa: Universidade de Lisboa; 2015.

28. Costa IP, Costa SP, Pimenta CJL, Lima RF, Brito MJM. A importância das atividades lúdicas para a saúde mental do idoso institucionalizado: um relato de experiência. Anais do II Congresso Brasileiro de Ciências da Saúde; 14-16 jun 2017; Campina Grande, Brasil. Campina Grande: Realize; 2017.

29. Braga CD, Marques AL. Comunicação e mudança: a comunicação como elemento facilitador do processo de mudança organizacional. Rev FAE. 2008;11(1):9-17 [acesso em 5 dez 2019]. Disponível em: https://revistafae.fae.edu/revistafae/article/view/254/173.

30. Freire P. Extensão ou comunicação? Rio de Janeiro: Paz e Terra; 1983.

31. Golinelli RT, Massi G, Krüger S, Santos IB, Paisca AB, Berberian AP, et al. Autopercepção de idosos a respeito de suas condições auditivas, de sua escuta e de suas estratégias de comunicação. Distúrb Comum. 2019;31(2):317-27 [acesso em $11 \mathrm{dez} 2019$ ]. Disponível em: http:// revistas.pucsp.br/dic/article/view/38578/29270.

32. Charon R. Narrative medicine: a model for empathy, reflection, profession, and trust. JAMA. 2001;286(15):1897-902.

33. Lourenço RCC, Massi G, Lima RR. Language and aging: a searchfor resignifications of life stories. Rev CEFAC. 2014;16(2):672-8 [acesso em 11 dez 2019]; 672-678. Disponível em: https://www.scielo.br/ scielo.php?script=sci_arttext\&pid=S1516-18462014000200672\&lng= en\&nrm=iso\&tlng=en.

34. Motta LB, Aguiar AC. Novas competências profissionais em saúde e o envelhecimento populacional brasileiro: integralidade, interdisciplinaridade e intersetorialidade. Ciênc Saúde Colet. 2007;12(2):363-72 [acesso em 20 jan 2020].

REVISTA BRASILEIRA DE EDUCAÇÃO MÉDICA

9 44 (4) : e170; 2020 
Disponível em: https://www.scielo.br/scielo.php?script=sci arttext\&pid=S1413-81232007000200012.

35. Cabral BESL, Melo JAB, Silva KR. Sociedade senescente: análise de vínculos sociais numa instituição de longa permanência em Campina Grande - PB. Memorialidades. 2012;9(18):89-121.

36. Michaelis dicionário escolar língua portuguesa. São Paulo: Melhoramentos; 2016.

37. Corrêa RGCF, Santos RAAS, Rolim ILTP, Coutinho NPS. Atenção no cuidado do idoso: infantilização a desrespeito à autonomia na assistência de enfermagem. Rev Pesq Saúde. 2016; 17(3):179-83.

38. Brasil. Envelhecimento e saúde da pessoa idosa. Brasília: Ministério da Saúde; 2006.

39. Luna WF, Melo JAB, Vaz CHM. Entre chegadas e partidas: conversas intergeracionais no projeto de extensão saúde do idoso. Revista Saúde em Redes. 2019;5(3):177-91 [acesso em 15 dez 2019]. Disponível em: http://revista.redeunida.org.br/ojs/index.php/rede-unida/article/ view/2429/423.

40. Brasil. HumanizaSUS: documento base para gestores e trabalhadores do SUS. Brasília: Ministério da Saúde, 2010.

41. Motta $\mathrm{AB}$. Idade e solidão: a velhice das mulheres. Revista Feminismos. 2018;6(2):88-96 [acesso em 20 fev 2020]. Disponível em: https:// portalseer.ufba.br/index.php/feminismos/article/view/30390/17912.

42. Neri AL, Freire SA. E por falar em boa velhice. Campinas: Papirus; 2000.

43. Moimaz SAS, Gabin CAS, Silva MM, Joaquim RC, Saliba
NA. Projeto "Sempre Sorrindo": 10 anos de atenção ao idoso institucionalizado. Rev Bras Pesqui Saúde. 2011;13(1):46-51 [acesso em 25 fev 2020]. Disponível em: https://repositorio.unesp.br/ bitstream/handle/11449/133401/ISSN1516-6228-2011-13-01-46-51. pdf? sequence $=1$ \&is Allowed $=y$

\section{CONTRIBUIÇÃO DOS AUTORES}

Willian Fernandes Luna e Roseli Vernasque Bettini foram responsáveis pela orientação da investigação. Renata Keiko Watanabe e Mariana Miki Shiroma foram responsáveis pela elaboração do projeto de pesquisa e pela coleta de dados. Mayara Bosquê Marangon e Michele Cheh Hui Liang Chung foram responsáveis pela coleta de dados e pela escrita do artigo. Todas as demais etapas foram realizadas por todos os autores.

\section{CONFLITO DE INTERESSES}

Os autores informam que não há conflito de interesses na escrita do manuscrito em questão. Informam ainda que este projeto não recebeu financiamento.

\section{ENDEREÇO PARA CORRESPONDÊNCIA}

Michele Cheh Hui Liang Chung. Rua Casarejos, 835, Vila Mogilar, Mogi das Cruzes, SP, Brasil. CEP: 08773-300.

E-mail: michachele@gmail.com 